\title{
Formação de professores como resgate social no contexto amazônico: uma proposta contra-hegemônica
}

\author{
Training of teachers as social rescue in the amazon context: \\ a counter-hegemonic proposal
}

Valmir Flores PINTO1

Resumo

A partir proposta da educação contra-hegemônica inspirada em Antonio Gramsci, a formação de professores no contexto amazônico brasileiro está carregada de desafios. Nessa perspectiva, educação é um canal para entender e formar o sentido de classe. Trata-se dos primeiros passos para a contra-hegemonia dos menos favorecidos diante da hegemonia dos dominantes na sociedade civil e política. O objetivo é um estudo sobre a qualificação formativa dos profissionais de educação para a atuação na base. $\mathrm{Na}$ metodologia procuramos combinar elementos da literatura dialética histórico-crítica e qualitativa a partir da realidade pesquisada: as realidades geográficas, sociais, econômicas e políticas do sul amazônico.

Palavras-chave: Amazônia. Educação. Formação de Professores. Hegemonia.
Abstract

Based on the proposal of counter-hegemonic education inspired by Antonio Gramsci, teacher training in the brazilian amazon context is fraught with challenges. In this perspective, education is a channel for understanding and forming the sense of class. These are the first steps towards the counter-hegemony of the less favored before the hegemony of the dominant in civil and political society. The objective is a study on the formative qualification of the professionals of education for the performance in the base. In the methodology we seek to combine elements of historical-critical and qualitative dialectical literature based on the researched reality: the geographic, social, economic and political realities of the amazonian south.

Keywords: Amazônia. Education. Teacher Training. Hegemony.

1 Doutor em Estudos Ensino Superior pela Universidade de Aveiro-Portugal e Educaçáo-Universidade Federal do Amazonas. Grupo de Investigação Relação Educativa e Aprendizagem UFAM/CNPq; Professor de Filosofia da Universidade Federal do Amazonas. End.: Rua 29 de Agosto 786, Humaitá, AM. CEP: 69800-000 Tel.: (92) 33051181 - Ramal 2191-Direção; 2198-Pós-Graduação. Email: $<$ valmirfloresp@gmail.com>.

R. Educ. Públ. v. 27

n. $65 / 1$

p. $343-364$ maio/ago. 2018 


\section{Introdução}

A reflexão em torno de uma proposta política e pedagógica de educação para o contexto da Amazônia brasileira necessita de envolvimento, náo apenas nos padróes curriculares, mas também de propostas que possibilitem o acesso à formação de profissionais que atuarão na educação básica e no ensino superior. Nesse sentido, o canal da educação apresenta-se como um mecanismo dinâmico de contra-hegemonia, tendo em vista que as necessidades e os desafios no contexto amazônico são bem específicos em relação às demais regióes brasileiras.

Assim, educação-cidadania e educação-política tornam-se binômios fundamentais no conjunto da formação e da pesquisa acadêmica. Os decretos governamentais são ferramentas que poderão colaborar no sentido de políticas públicas de qualidade e qualificação na educação. No entanto, há que considerar investimentos em diversas medidas, como ensino integral de seus cidadáos e práticas políticas virtuosas. Dessa forma, o nível considerado elevado ou bom na qualidade de vida e na estrutura social somente poderá alcançar padróes mais aceitáveis se combinado com outras medidas estruturantes e na mudança dos padrôes rígidos e hegemônicos de orientação concentradora e excludente.

Nesse sentido, desenvolvemos as reflexóes amparadas em alguns conceitos de Antonio Gramsci a partir de uma realidade específica: o sul do Amazonas. Com a análise ancorada em teorias e algumas entrevistas ${ }^{2}$, propomos que a formação e a qualificação dos profissionais da educação, em todos os níveis, não poderão resolver os problemas de cunho sociais e políticos de forma isolada. A formação da consciência cidadã certamente passa, em boa parte, pelo ambiente escolar/ acadêmico, mas requer parcerias com a sociedade civil e política.

\section{Educação um núcleo cultural contra-hegemônico}

Os conceitos de educação, cidadania e política na atual conjuntura têm influências de diversas correntes de pensamento e, em certo sentido, estão universalizados. A compreensão hegemônica à luz das contribuições de Antonio

2 Os critérios adotados para a escolhas dos sujeitos entrevistados foram: envolvimento com a práticas e desenvolvimento de atividades junto ao ensino, preferencialmente o ensino superior. Foram entrevistados 18 acadêmicos de cursos de licenciatura do Instituto de Educação, Agricultura e Ambiente, do campus da Universidade Federal do Amazonas, na cidade de Humaitá, AM; cinco professores e dois técnicos do mesmo campus; e três egressos que atuam no ensino fundamental da Rede Estadual de Humaitá, AM. 
Gramsci (1891-1937) que envolve as açóes políticas no contexto educacional, além do modelo de educação unitária, também perpassa por um processo de mundialização, por alguns estudiosos e pesquisadores que também abordam a globalização. Constantemente somos convocados a ingressar no quadro de formação acadêmica por meio de propagandas de instituiçóes públicas e privadas. Para isso, o mecanismo principal é a formação para o mercado, a competitividade e o lucro (PARASKEVA, 2009).

Por outro lado, os apelos em relação à ecologia, aos cuidados com o ambiente, com as pessoas, a luta contra os estados de miséria e a favor da sustentabilidade, formam outra face da realidade. Todos precisam ser educados para esse mundo plural, multidimensional, complexo e internacional, também chamado por Bauman $(2000,2009)$ de sociedade líquida. A hegemonia educacional não visa mais apenas uma classe, como era o foco de Gramsci, mas ainda permanece o enfoque de classe. Trata-se de um apelo ao bem-estar da comunidade, seja local, nacional ou internacional, a partir de uma ótica inclusiva.

Os escritos de Gramsci relativos à questáo político-pedagógica estáo marcados por uma conjuntura específica em que se manifesta a sua crítica ao fascismo italiano e a problemática do capitalismo de entáo. Portanto, o antifascismo apresentado por Gramsci tem um motivo de ser (GRAMSCI, 2011). Com o propósito de uma nova interpretação da história, da economia e da cultura dos italianos, faz uma pesquisa profunda em torno do Risorgimento, que significa renascença, ressurreição, empregado no século XIX para designar o movimento ideológico e político que contribuiu para unificar e democratizar a Itália.

O Risorgimento começa com a reivindicação de um poder governamental puramente laico diante do poder da Igreja Católica Romana. Nesse período, conclui-se que o fascismo é a continuação de uma política tradicional, de uma classe dirigente e do capitalismo em luta com a maioria da população (SANTARELLI, 1979).

Algumas questóes que foram abordadas na perspectiva de Antonio Gramsci continuam na pauta da discussão na sociedade atual e há contextos que refletem a "[...] consciência enlatada [...]", o que torna o "[...] exercício da possibilidade [...]" (SANTOS, 2006, p. 187) para a cidadania mais desafiadora.

Há um texto de Marx e Engels, o Manifesto Comunista -1848, que retrata uma descrição aproximativa da atualidade do ponto de vista econômico, social e político e, conforme Boaventura de Sousa Santos (2006), também uma espécie de profecia da globalização hegemônica, um retrato da realidade mundial capitalista.

A burguesia, pela sua exploraçáo do mercado mundial, deu uma forma cosmopolita à produçáo e ao consumo 
de todos os países. Para grande pesar dos reacionários, roubou à indústria base nacional em que assentava. As primitivas indústrias nacionais foram aniquiladas, estão ainda dia a dia a ser aniquiladas. São desalojadas por novas indústrias cuja introdução se torna uma questão de vida ou de morte para todas as naçóes civilizadas, por indústrias que já não trabalham matérias-primas nacionais, mas matérias-primas oriundas das zonas mais afastadas, e cujos produtos são consumidos não só no próprio país, mas em todos os continentes ao mesmo tempo. Em lugar de velhas necessidades, satisfeitas pelos produtos do país, surgem necessidades novas que exigem para a sua satisfação os produtos dos países e dos climas mais longínquos. Em lugar da velha autossuficiência e do velho isolamento locais e nacionais, surgem um intercâmbio generalizado e uma dependência generalizada das naçóes entre si. (MARX; ENGELS, 1982, p. 110).

O capitalismo, com suas promessas de felicidade, globalizou-se e o socialismo real falhou. Os males denunciados no Manifesto continuam táo ou mais atuais. "A distância entre ricos e pobres nunca foi tão grande como é hoje em dia. Faz-se necessário, não um, mas vários novos Manifestos capazes de mobilizar todas as forças progressistas do mundo" (SANTOS, 2006, p. 203-204).

É possível ver a educaçáo como um paradigma de mudança e de cidadania? A chave de interpretação a essa indagação está na superação do senso comum, inclusive do imposto pela sociedade de consumo atual, para um bom senso que afirme a educabilidade do ser humano e que supere os mecanismos de exclusão. A chave da hegemonia, entendida como direção, está no interpretar e conceituar o fato educativo e relacioná-lo com as estruturas sociais para o bem comum da sociedade.

Nesse sentido, não existe, pois, uma educação neutra, desvinculada dos fatores ideológicos e políticos de uma classe social. Seja na hegemonia, seja na contrahegemonia, a educação visa às relaçóes sociais entre as pessoas para manter ou modificar uma estrutura, envolvendo alguns elementos, "[...] como o indivíduo, os outros e a natureza" (GRAMSCI, 1981, p. 40).

Nesse embate na sociedade, pela dominação ou direção, a classe dominante procura manter a sua hegemonia e reproduzir as formas de dominação. $\mathrm{Na}$ conjuntura que se desenvolve essa disputa a educação é um dos principais mecanismos utilizados para a disputa por poder. A forma para superar tal poder passa pela contra-hegemonia do saber educacional. "A dissimulação do saber e o afã de reificá-lo apontam o fato de que ele também é contraditório, já que 
nascido no contexto de uma totalidade contraditória, histórica e provisória" (CURY, 1985, p. 69).

Vê-se, nessa perspectiva, que a educação tem um caráter político-pedagógico. Isso é, em qualquer nível a educação visa atingir o ser humano na sua dimensão política, proporcionando um caráter de cidadania à sua vida e à sociedade, para não depender apenas dessa ou daquela instituiçáo educacional. A educação, a partir dos modelos que são apresentados aos estudantes, principalmente de nível superior, tem muito de um mecanismo de ajuste à ordem vigente, que oculta as contradiçóes sociais e mantém a sociedade coesa por meio do discurso igualitarista. Ou seja, criam-se mitos de felicidade e progresso na luta de todos contra todos, isso é, um individualismo extremo.

Os indivíduos são convocados a serem responsáveis pelo seu destino, pela sua sobrevivência e pela sua segurança, gestores individuais das suas trajetórias sociais sem dependências nem planos predeterminados. No entanto, esta responsabilização ocorre de par com a eliminaçáo das condiçóes que a poderiam transformar em energia de realização pessoal. O indivíduo é chamado a ser o senhor do seu destino quando tudo parece estar fora do seu controlo. A sua responsabilização é a sua alienação; alienação que, ao contrário da alienação marxista, não resulta da exploração do trabalho assalariado, mas da ausência dele. (SANTOS, 2006, p. 278).

O processo educativo é a chave da tomada de consciência para a superação do senso comum, assumindo outra hegemonia organizacional que "[...] dê coerência e critique os elementos contidos no senso comum e seja capaz de elaborar outra hegemonia filosófica explícita" (CURY, 1985, p. 75-77). Portanto, cria-se uma contra-hegemonia pela educação que passa pelo crivo do próprio saber.

O saber permite-nos perceber as contradiçóes, seja por parte da classe dirigente, seja por parte dos dirigidos. Entende-se que a educação é o núcleo da contra-hegemonia na sociedade, pois, mesmo no ensino superior, há obstáculos a serem superados para transformá-lo caráter universitário e acessível à sociedade.

Uma Instituição de Ensino Superior (IES) que sirva de motor ao desenvolvimento social e cultural há que inserir elementos de racionalização na estrutura, de decisóes dentro dos contextos sociais em que se insere principalmente os locais e regionais - e incorporar as expectativas e projetos dos docentes, discentes e sociedade local. A educação como tal e a consolidação da cidadania são as vias condutoras de um núcleo cultural contra-hegemônico. Assim, a não existência unificada entre a proposta de inserção da educação com 
os contextos sociais assume um caráter de denúncia. Exemplos disso são os conglomerados de escolas profissionalizantes superiores, com uma Reitoria que lhes é superposta, com propostas de expandir-se quantitativamente, sem melhoria de qualidade à pesquisa, à produtividade do ensino e ao recrutamento de pessoal (PAOLI, 1981).

As reivindicaçóes por investimentos em educação, principalmente nos anos ou ciclos iniciais, como uma bandeira de muitos autores e críticos da sociologia e da ciência da educação, não é novidade. Porém, se essas reivindicaçóes continuam sempre na pauta das discussóes e propostas dos pesquisadores, educadores e em muitos discursos de alguns membros dos legislativos dos Estados, significa que elas não foram estabelecidas ou precisam ser melhoradas a cada dia.

O momento contra-hegemônico não será mais apenas de uma instituição, mas o conjunto das ações criado pela educação e pela cultura na sociedade, que se manifesta na superestrutura, pois, além da sua função social, a educação tem uma significação política.

É justamente nesse aspecto da educação que consiste a importância do legado de Antonio Gramsci, em que o indivíduo não simplesmente reproduz as experiências anteriores, mas soma a essas experiências a sua visão e avaliação, tornando-se capaz de organizar e reestruturar a sociedade (FREITAG, 1978), pois a educação exerce mediação em todas as relaçóes sociais, e não apenas no que se refere à educação formal (BRANDÃO, 1981).

A educação se estrutura como instrumento de libertação exatamente quando se apresenta no âmbito da sociedade civil como uma contra ideologia ou contrahegemonia, em relação ao modelo educacional vigente como instrumento estratégico de dominação. Uma vez que toda relação hegemônica é também uma relação pedagógica, a escola e a educação tem uma dupla função: de conservar e também de minar as estruturas do modelo econômico e social, quando não responde às urgências e necessidades da sociedade (GIMENO SACRISTÁN; PERÉS GOMÉZ, 1998).

Nesse estágio da discussão surgem questôes relacionadas à educação e à cidadania, tanto otimistas como pessimistas. ${ }^{3}$ Otimismo por atribuir à educaçáo um caráter messiânico, salvador, capaz de, por si só, corrigir todas as imperfeiçóes das pessoas: a remoção da ignorância se faz pela educação. Pessimismo, dado o

3 Ver as influências da pedagogia crítica desenvolvida por Paulo Freire (1921-1997) e a Teoria Crítica da Escola de Frankfurt, por meio de Herbert Marcuse (1898-1979), Max Horkheimer (1895-1973), Theodor W. Adorno (1903-1969) e Jürgen Habermas (DÜSSELDORF, 1929; AYUSTE, 1997), em que o educando se torna sujeito, recria o conhecimento para intervir na realidade e modificá-la. 
caráter instrumental atribuído a essa educação, concebida somente como agente de ideologia dominante, uma educação que está destinada a perpetuar o sistema social vigente (CORTELLA, 1993). É esse ambiente do espaço físico e do espaço político e ideológico, que não é algo imutável, mas dinâmico, que está a ser construído e destruído, permanentemente, seja pelo homem, seja pelas forças da natureza. Educação e cidadania ganham, dessa forma, um cunho de protesto contra as generalizaçóes, a adaptaçáo, o conformismo e a mera transmissão de conhecimentos.

O núcleo cultural contra-hegemônico ocorre na mudança de comportamento e mentalidades gerada ao longo de um processo educativo. Mudanças cívicas náo ocorrem por decretos governamentais, mas no aprendizado de valores por meio de uma educaçáo formal e informal acentuada e dedicada. Todos os povos que hoje têm um nível considerado bom ou elevado de desenvolvimento social e humano investiram e se comprometeram com diversas medidas, como: o ensino integral de seus cidadáos, práticas de açóes cívicas e políticas virtuosas.

O reflexo dessa mentalidade e formaçáo ultrapassa o ambiente escolar, pois, se há uma cultura do consumo, de levar vantagem em tudo e sobre todos, do desinteresse com as coisas públicas, a mudança passa por uma postura contrahegemônica desse comportamento. A ignorância é a causa, às vezes involuntária, que proporciona o mau funcionamento da sociedade. $\mathrm{O}$ objetivo da educaçáo como um princípio hegemônico da cidadania está em instaurar uma nova cultura para, paulatinamente, de geração em geração, quebrar o círculo vicioso e criar um processo consciente de formação.

Não há um único modelo de cultura no qual se estabeleçam os comportamentos humanos, mas incluem-se construçóes culturais na atual conjuntura desigual de globalização. "A globalização da cultura, tal como a globalização da economia, é um processo muito desigual e contraditório" (SANTOS, 2006, p. 279). Na Europa das Luzes, com destaque ao século XVIII, Schiller declara: "Escrevo como cidadão do mundo. Cedo abandonei a minha pátria para trocá-la pelo gênero humano" (SCHILLER apud LIPOVETSKY; SERROY, 2010, p. 13).

Esse universal humanista se identifica com o ideal liberal, com o alargamento de amor à humanidade. Em nosso tempo, a partir da metade do século XX, aparece uma nova fase com traços diferentes do ideal de cidadáo do mundo.

O mundo sem fronteiras dos capitais e das multinacionais, do ciberespaço e do consumismo. Já não se limitando à esfera do ideal, mas remete para a realidade planetária hipermoderna, onde a economia do mundo se organiza segundo um modelo único de normas, de valores e objetivos - o ethos e o sistema tecnocapitalista - e onde a 
cultura se impóe como mundo econômico de pleno direito. (SCHILLER apud LIPOVETSKY; SERROY, 2010, p. 13).

Com o desenvolvimento de novas tecnologias e das indústrias da cultura e da comunicação, se remodela nosso conhecimento do mundo pela facilidade de acesso às informaçóes. Ressalta-se, que nesse mundo do espetáculo da informação pela mídia e Web algumas informaçóes correm o risco de se transformar em armas de destruição da cultura em um contexto mais amplo, como a massificação do pensamento, dissolução dos laços sociais, manipulação de opiniôes, despolitização e mercantilização geral da cultura, além de uma ampla divulgação do individualismo e do consumismo.

Nesse contexto de hipermodernidade a racionalização globalizante e os mercados impóem os critérios para a cultura (LIPOVETSKY; SERROY, 2010). No entanto, não há nenhuma garantia de que teremos resultados positivos. As crises constantes do neocapitalismo ${ }^{4}$ dão sinais desse cenário de incertezas, assim como a desconfiança generalizada tanto nas próprias pessoas, como nos partidos políticos e instituiçôes financeiras. Esses são motivos de desconfiança e descrédito. Se o socialismo real acabou, o capitalismo globalizado náo traz segurança e cria ansiedade. A primeira década do século XXI é uma amarga realidade dessa conjuntura.

Pode parecer pessimismo, mas, infelizmente, é uma realidade, e o mal-estar ético e cultural é fruto de democracias sem respeito pela cidadania e direitos humanos básicos, isso do primeiro ao terceiro mundo, com poucas exceçóes. Ressalta-se que não é novidade os períodos de certa desorientação e mal-estar.

A cultura é um instrumento de identificação social e pessoal, da vida econômica, e uma espécie de biopoder pessoal que é determinado pelo biopoder

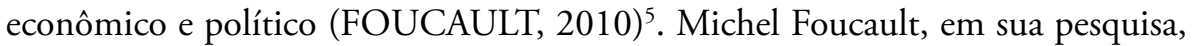
investiga e antecipa as novas formas de controle biopolítico, não mais sob o eixo dos exageros do poder soberano estatal, mas agora segundo o eixo flexível das economias de mercado influenciadas pelo neoliberalismo econômico da Escola

4 Crises económicas como: crises mexicanas, de 1982 e 1995; crise asiática, de 1997; da Rússia e do Brasil, em 1988 e 2009; Argentina, em 2001; Estados Unidos da América, em 2008; E.U. - Uniāo Europeia, em 2009, com grandes sinais de recessão, quebra de instituiçôes financeiras. Além disso, os escândalos financeiros e desigualdade de renda crescente (WOLF, 2009).

5 Foucault chega aos conceitos de biopoder e biopolítica ao vislumbrar o aparecimento, ao longo do século XVIII e, sobretudo, na virada para o século XIX, de um poder disciplinador e normalizador que se concentrava na figura do Estado e se exercia a título de política estatal que pretendia administrar a vida e o corpo da população. 
de Chicago. Foucault compreende que, sob o neoliberalismo econômico do pós-guerra, o homem havia sido compreendido e mesmo fixado em termos do homo oeconomicus, isso é, como agente econômico que responde aos estímulos do mercado de trocas, mais do que como personalidade jurídico-política autônoma (FOUCAULT, 2010). Este homo oeconomicus não é apenas um empreendedor qualquer no mercado de trocas, mas sim um empreendedor de si mesmo, tomando-se a si mesmo como seu próprio produtor de rendimentos.

No regresso da cultura, seja como um bem social ou como um bem econômico, e esse é visto como oportunidade, seja para rever, reavaliar e mudar as posturas e atitudes, seja para criar novas possibilidades. Como há o risco da uniformizaçáo e padronização que afetam os produtos, imaginários e gostos, há também as oportunidades de crescimento em conhecimento, uma vez que nunca se produziu e difundiu com tanta rapidez, pela internet, cinema, televisão, publicaçóes de livros, jornais, para citar alguns meios.

Para a implantação da civilização da cultura, necessitamos de empenho político e recursos da sociedade civil, por meio do diálogo e da escuta, do respeito às diversidades culturais, com a educaçáo a desenvolver um papel fundamental nessa mudança de paradigma. A referida mudança, conforme já assinalava Antonio Gramsci, "[...] não será de um ataque frontal ao Estado, mas produto de uma longa, lenta e tenaz guerra de posiçóes na sociedade civil. Uma expansão molecular de influência cultural e organizativa” (GRAMSCI apud GINSBORG, 2008, p. 63).

Agindo dessa forma, a educação assume um processo contra-hegemônico de mudança e "[...] isso só será possível se for adotada uma política de direitos diferentes da liberal hegemônica, e se tal política for concebida como parte de uma constelação mais ampla de lutas pela emancipação social" (SANTOS, 2006, p. 401).

As políticas de emancipação educacional precisam ser pensadas para reinventar um novo processo hegemônico no seio da sociedade civil e política; para isso, pode-se utilizar algumas tradiçóes, isso é, aproveitar o que há de melhor no antigo e aprimorar perante os desafios atuais. Esse processo articula-se a um nível que denominamos resgate social, que passamos a desenvolver na etapa seguinte.

\section{Educação e Resgate Social}

O segundo momento da contra-hegemonia da educação dar-se-á pela ação para a cidadania por meio do resgate e da afirmação das conquistas sociais. $\mathrm{O}$ primeiro desafio, nessa questão, está na própria concepção de cidadania, na superação de uma leitura burguesa dessa concepção. A grande perspectiva de cidadania ocidental, com ênfase e visibilidade política e ideológica, se deu com 
a Revolução Francesa (1789), em que o capitalismo criou o moderno operário. "O capitalismo criou a abstração do indivíduo, do cidadáo com direitos e deveres iguais perante a lei sem declarar que esta era a sua lei” (DIAS, 2010, p. 144).

A ordem do capital propóe a uniformização da sociedade ao propor a igualdade jurídica formal, chamando-a de cidadania. Com isso, esconde as fissuras e contradiçóes do sistema. Conforme Dias (2010, p. 174), de uma situação que deveria ser campo de luta, "[...] a cidadania passa a ser vista como construtora de consensos, sendo uma das formas privilegiadas de subalternizar os trabalhadores, as classes instrumentais, que se pensam como iguais aos seus dominantes."

Com os tempos hipermodernos ${ }^{6}$ tenta-se naturalizar as coisas e os acontecimentos, acompanhados de uma des-historização. Assim, torna-se quase impossível os subalternos falarem e serem ouvidos, pois a referência para o estilo de vida, de família, de escola, de trabalho e até de lazer e socialização é o modelo burguês. Tornou-se senso comum, criou-se um processo hegemônico no qual as pessoas subalternizadas pensam, agem e vivem como se fossem burguesas.

A proposta neoliberal é transformar as pessoas em consumidores e, no máximo, em reivindicadores particulares com status de empreendedores, pois o consumidor personifica o privado, o mercado e o indivíduo. Em termos de referências teóricas e práticas, o neoliberalismo tem sido um ponto essencial para avaliar e explicar essas mudanças, já que funde os elementos "[...] políticos e econômicos da economia política na atual conjuntura" (CLARKE et al., 2007, p. 17).

Como proposta de resgate social convém resgatar o sentido de classe para uma nova sociabilidade, pois simplesmente aceitar os conceitos e práticas atuais ditados pelo mercado e o capital significa permanecer na subalternidade. Conforme afirma Dias (2010, p. 150): "Só poderão afirmar-se como autônomas se elas, as classes, afirmarem os seus projetos, sua sociabilidade, historicidade e cultura."

O canal da educação é essencial para entender e formar o sentido de classe. Isso requer um insistente e longo projeto de reeducaçáo para uma nova sociabilidade na perspectiva de transformação social. Trata-se dos primeiros passos para a contra-hegemonia dos menos favorecidos perante a hegemonia dos dominantes, pois se o atual projeto neoliberal for o único verdadeiro, fica vedada a própria

6 Termo utilizado por Lipovetsky (2004, p. 26) para explicitar os valores criados na modernidade. "Hipermodernidade: uma sociedade liberal, caracterizada pelo movimento, pela fluidez, pela flexibilidade; indiferente como nunca antes se foi aos grandes princípios estruturantes da modernidade, que precisaram adaptar-se ao ritmo hipermoderno para não desaparecer”. 
possibilidade de superação da realidade classista (BOBBIO, 1986). Não há como admitir a harmonia social numa situação de profunda desigualdade. A linguagem dominante cria o senso comum de que todos somos iguais.

A leitura feita pela burguesia iluminista da Revoluçáo Francesa de que todos são iguais perante a lei, não passa de uma abstração do indivíduo-cidadão. Isso dá reconhecimento institucional à burguesia e passa a ser reconhecido como tal pelo senso comum. Como afirmam Marx e Engels (1976, p. 65): "O Estado suprime com as diferenças de condição, de nascimento, de profissão e cultura, ao declarar que não são diferenças políticas, mas que todos são iguais sem considerar as particularidades."

Para a superação do senso comum e criação de uma nova consciência de classe, os intelectuais desenvolvem um papel fundamental. Trata-se de romper com o pensamento dominante, e isto "[...] requer dos intelectuais das classes subalternas a recusa de todo e qualquer determinismo, seja ele economicista ou politicista” (DIAS, 2010, p. 153). Qualquer forma de determinismo não é boa para a sociedade que se quer democrática.

Os atores sociais são importantes na formação dos intelectuais da classe e seus simpatizantes da causa. Esse processo irá permitir sair do imediatismo, do senso comum e construir uma racionalidade com profissionais da educação, pesquisadores, escritores e também aqueles que, mesmo não atuando diretamente na formação, pensam e desenvolvem práticas de cidadania na sua classe e na sociedade. Exige-se formaçáo na academia e na organização quotidiana nos movimentos sociais, políticos e sindicais.

As distâncias que ainda existem entre intelectuais e as classes dos trabalhadores precisam ser diminuídas. Essa questão é predominante e determinante, como já afirmara Gramsci ao refletir sobre a participação e formação dos intelectuais a partir do grupo social: “[...] a questão continua a ser a distinçáo entre intelectuais como categoria orgânica de cada grupo social fundamental e intelectuais como categoria tradicional" (GRAMSCI, 2010, p. 23).

A educação pode desenvolver esse papel de assessoria e processo formativo para contribuir no resgate social a partir da articulação dos ideais e projetos entre as diversas categorias, abertura para discussão, negociação, mudança e parcerias com outros atores políticos e sociais importantes, contribuindo, assim, para uma nova sociabilidade. $\mathrm{O}$ processo contra-hegemônico terá, dessa forma, uma ação diversificada para a articulação do novo sujeito revolucionário, e para isso deverá contar com amplo campo de alianças.

Os movimentos feministas, dos homossexuais, dos ecologistas, dos estudantes, da diversidade religiosa, das minorias raciais, entre outros, que não necessariamente têm um corte de classe, para terem realizadas as suas reivindicaçóes, precisam 
de uma nova ordem social. Podem articular suas demandas particulares com as demandas universais da transformação social (JOSÉ; LEITE, 2002).

O resgate das conquistas sociopolíticas é outra ação parceira da educação nesse processo hegemônico para a reconfiguração da cidadania. $\mathrm{Na}$ primeira década do século XXI algumas questóes voltam à pauta do dia nas discussôes em âmbito internacional: trabalho, dignidade da vida humana, ecologia, educação ambiental, questóes de gênero, sexualidade, poder, diversidade cultural e religiosa, sustentabilidade, família, etc. Ao mesmo tempo em que há uma forte pressão dos mercados e das indústrias culturais e de consumo para uma homogeneização, aumentam também as solicitações comunitárias de diferença: quanto mais o mundo se globaliza, mais alguns particularismos culturais aspiram afirmar-se nele. "A uniformização globalitária e a fragmentação cultural caminham ao par" (LIPOVETSKY; SERROY, 2010, p. 23).

As grandes utopias, principalmente do século passado (século XX), sofreram abalos diante dos terríveis acontecimentos que afetaram a humanidade, e muitos continuam a provocar danos, como os totalitarismos, capitalismo neoliberal, consumismo, preconceitos raciais, religiosos e culturais, falta de solidariedade, terrorismos, banalizaçáo dos meios de comunicação, democracia sem amor pela cidadania, entre outros males que causam desorientação.

Diante desse cenário sombrio, têm-se oportunidades e razóes para resgatar e reintroduzir conquistas com a ajuda das novas tecnologias. As conquistas trabalhistas precisam ser analisadas e retomadas, pois, apesar dos avanços, ainda há trabalho escravo, perda de conquistas - como ocorreu recentemente no Brasil com a Reforma Trabalhista de 2017 - e não garantia da empregabilidade.

A falta de segurança em relação ao emprego e ao pagamento justo impulsionou a explosão de movimentos sociais no mundo, juntamente com o direito trabalhista, também conhecido como humanismo jurídico (COSTA, 1999), que vê no ser humano o caminho para todas as coisas e no princípio da proteção social a base do Direito do Trabalho.

O Direito do Trabalho, no entanto, é o produto de uma sociedade desigual e visa favorecer e proteger os excluídos do processo econômico e desprovidos das vantagens que a sociedade de consumo oferece. O salário mínimo regulado (nem sempre justo), diminuição das horas diárias de trabalho, regulamentação das férias, direito de greve, descanso semanal, participação e reconhecimento das mulheres no trabalho profissional, direito de organização sindical, entre outras conquistas, significam o reconhecimento e a capacidade de atuação política na sociedade por meio das diversas categorias de trabalhadores (MARTINS, 2003; NASCIMENTO, 2003).

A educação, no seu processo formativo, poderá desenvolver importante papel de ação no resgate das conquistas trabalhistas, não apenas com uma leitura histórica, 
mas com formação sobre as reais situações em que se encontram as políticas laborais, sobre os direitos dos trabalhadores, as propostas econômicas e sociais e a importância de qualificação e organização dos trabalhadores como categorias.

A educação não é mera transmissão de conteúdos e conhecimentos ou da tradição, mas é um educar-se pelo Outro, é tornar-se, um vir-a-ser, estar em perene movimento. Não é simplesmente negar a tradição, mas a sua apreensão, um verdadeiro processo de reconstrução na formação: tradição, renovação e respeito pelas diferenças, pelo outro.

\section{Cidadania e Educação}

A partir das consideraçôes elaboradas anteriormente em relação à educação à luz de Antonio Gramsci é possível um único conceito de cidadania? Com certeza não! Sua conceituação é histórica e depende da percepção e do momento em que ela é forjada. Assim, uma coisa é ser cidadão nas diversas realidades brasileiras. Outra, ser cidadão na pólis (grifo nosso) grega ou na Revolução Francesa ou para momentos de luta, como afirma Patrice Canivez (1991, p. 37):

Cidadania veicula a lembrança de uma época mítica; é um engajamento político, o serviço a uma causa ou uma expressão de um dever. A noção náo parece feita para os dias comuns; não adquire realidade no trabalho cotidiano ou nas relaçóes privadas, de família ou de amizade. É nos tempos de crise, ou de guerra, que o questionamento dessa existência comum e o perigo corrido por toda a comunidade lembra ao indivíduo que ele pertence a um Estado. Nessas condiçôes, a cidadania deveria ser objeto de comemoraçáo.

Tivemos momentos na sociedade brasileira em que a população foi transformada em espectadora da política sob os diversos mecanismos - repressóes, eleiçóes, favores, compras de votos e falta de oportunidades, em que não se teve quaisquer, ou poucas, oportunidades para o exercício do poder. Apesar da situação de conquistas significativas na atualidade, a maioria da população brasileira ainda é composta por indivíduos e não cidadãos plenamente.

Por cidadão alguns entendem o indivíduo que possui os direitos políticos; outros, os deveres sociais; outros, os que têm acesso aos bens de consumo. Mas filosófica e sociologicamente falando, o cidadão está além dessas concepções. A palavra cidadão e seu significado histórico estão nas raízes, do latim "[...] civis, que designava o habitante da civitas, a Cidade-Estado romana; o civis, porém, 
não era um habitante qualquer, mas aquele que tinha interesses a defender junto ao Estado, pois era proprietário de terras" (RANCIÈRE, 1996, p. 37). O Estado era tomado como parte dele. Se voltarmos à pólis grega, encontramos uma compreensão de cidadão muito parecida, onde os considerados eram os homens adultos, proprietários, nascidos na cidade; estavam excluídos da cidadania as mulheres, as crianças, os escravos e os estrangeiros. $\mathrm{O}$ que conhecemos como cidadão grego é aquele homem que o filósofo Aristóteles (384 a.C.-322 a.C.) classificava como o indivíduo que, por nascimento e por posse, tomava parte nos negócios do Estado. Seja na raiz grega, seja na latina, a cidadania é definida como algo essencialmente ativo. Em termos mais atuais se pode dizer que a cidadania se constitui de direitos e deveres, ou possibilidades e necessidades de indivíduos articulados numa sociedade política.

Pelo fato de constatar que havia uma grande distância entre a base - massa - e as elites italianas em todas as instâncias de constituição do bem-estar social, está claro que a cidadania, na compreensáo de Gramsci, estava carente de elementos que a constituísse como tal. $\mathrm{O}$ resgate de valores que compóem o universo do cidadão nem sempre está ao seu alcance. $\mathrm{O}$ Estado poderá estar ausente, as autoridades constituídas negligentes, e como se diz popularmente: a corda arrebenta do lado mais fraco.

Mas há pessoas que podem contribuir com iniciativas no resgate da cidadania. Resgate? Exatamente! Pois ninguém, por natureza, nasce escravo, e sim tornase escravizado. A estrutura sócio-política e econômica muitas vezes transforma os seres humanos em espectadores. $\mathrm{O}$ intelectual da atualidade tem muito a contribuir, pois, como já afirmamos em tempo de crise, mesmo se recolhendo, ele não deixa de pensar.

A cidadania proposta e realizada pelas açóes, escritos e manuscritos de Antônio Gramsci parte de confrontos entre o operariado, empresários e o Estado Italiano. O foco maior era a questão salarial e o direito político de manifestar-se. Muito sangue e vidas foram perdidos para que a dignidade humana fosse reconhecida em parte, pois sua prisão e morte, juntamente com milhares de pessoas, pelo governo fascista, não bloquearam o pensamento e a indignação.

Ainda vivemos situaçóes politicamente desconfortantes em todo o mundo, de modo que a cidadania carece de entendimento e o quadro não é nada promissor. Como mostra Ester Buffa, o Brasil náo conseguiu nem mesmo realizar o ideal de cidadania burguesa da modernidade:

Os direitos do cidadáo, tantos os chamados direitos humanos - à vida, à saúde, à educação, à moradia - quanto os direitos civis - liberdade, igualdade jurídica, justiça -, 
que a partir do século XVIII foram sendo progressivamente realizados nos países capitalistas desenvolvidos são, pois, proposiçóes da democracia burguesa. Aliás, os direitos do homem e do cidadão foram reafirmados pela ONU, após a Segunda Guerra Mundial. Apesar disso, o Brasil, país capitalista, caracteriza-se por ser uma sociedade autoritária e hierarquizada em que os direitos do homem e do cidadão simples não existem. Não existem para a elite, de vez que ela não precisa de direitos porque tem privilégios. Está, pois, acima deles. Não existe para a imensa maioria da população - a massa no dizeres de Gramsci -, os despossuídos, pois suas tentativas de consegui-los são sempre encaradas como problemas de polícia e tratadas com todo o rigor do aparato repressor de um Estado quase onipotente. A extrema liberalidade com que é tratada a pequena elite corresponde à extrema repressão do povo, sobretudo quando os trabalhadores se organizam e lutam. Episódios recentes de nossa história revelam que nem mesmo a vida humana é encarada com alguma seriedade. (BUFFA, 2010, p. 28-29).

Trata-se, portanto, de construir uma cidadania para além da cidadania legal. Mas uma cidadania ativa, uma verdadeira forma de açáo política para o conjunto da sociedade e náo apenas para uma elite. A cidadania deve ser vista como a liberdade, inerente à condição humana.

Nessa situação o intelectual orgânico gramsciano, no contexto do Sul do Amazonas, onde desenvolvemos atividades acadêmicas de pesquisa e profissional, tem papel fundamental na linha das ciências humanas e sociais. Nesse sentido, a educaçáo poderá contribuir com os setores chamados populares e a vida acadêmica, considerando a elaboração de um projeto político-pedagógico que envolva questóes relacionadas à pesquisa científica, em vista do desenvolvimento econômico e social o mais democrático e inclusivo possível.

Durante muito tempo o intelectual esteve introjetado no sistema educativo formal, entendendo que a sua função era transmitir as suas ideias e não evidenciar as condições para a produção de conhecimentos, muito menos refletir sobre as condiçóes estruturais da sociedade, que muitas vezes dificultam o desenvolvimento social e cultural da própria sociedade.

A Amazônia, além dos elementos peculiares, como a geografia, o clima e a diversidade etnológica, requer um aprofundamento em torno da educação que envolve, de antemão, alguns dados e questóes, como:

- Há diferentes concepções de educação, e diante desse fato, é preciso refletir sobre elas tanto como formandos, quanto já na condição de professores; 
- Educação é formação? É instrução? É adestramento?;

- É desenvolvimento de competências e habilidades?

Retomamos as origens da Filosofia Ocidental, onde a Paideia é o termo grego para a educação, o "[...] ideal grego de formação humana" (JAEGER, 2013, p. 8). Ela compreendia a formação integral do ser humano e isso significava a formação física, a estética, no sentido da educação para o belo, e, consequentemente, para a arte, pois os gregos davam especial valor para a beleza. Também a formação moral, do caráter, da virtude, dos valores morais, entre outras. A Paideia incluía, portanto, a filosofia, entendida como o cultivo do bom e do belo. A educaçáo para os gregos era vista como uma arte e o educador como "[...] o oleiro [que] modela a sua argila e o escultor as suas pedras[...]" e, desse modo, "[...] a mais alta obra de arte que a sua aspiração se propôs foi a criação do homem vivo" (JAEGER, 2013, p. 13).

A referência à Paideia grega inspira, mais que desafios, posturas e propostas para a educação no contexto amazônico. Uma delas, a qual nos debruçamos é a formação de professores, principalmente para atuação na formação inicial. Há ofertas formativas regulares pelas IES na modalidade presencial e a distância, bem como o Plano Nacional de Formação de Professores da Educaçáo Básica (Parfor), em vigor desde 2009 (Portal MEC).

Apesar da expansão do ensino superior com programas federais, como o Restruturaçáo e Expansão das Universidades Federais (REUNI) e o Parfor, que atendem um contingente significativo, o contexto amazônico carece de instalaçóes físicas e investimentos no sentido de possibilitar o acesso e a formação de profissionais para atuarem na educação em todos os níveis.

A efetiva contribuição com elementos de cidadania na formação profissional é um direito dos profissionais da educação e da sociedade. Em termos de políticas públicas no Brasil, a oferta é grande, mas nem sempre atende a real situação tanto dos professores como da sociedade, onde eles desempenham suas funçóes acadêmicas.

Algumas situaçôes aparecem com muitas carências, como o caso do Sul do Amazonas, em específico na região de atuação do campus da Universidade Federal do Amazonas na cidade de Humaitá. Conforme levantamento realizado para este estudo e dados disponíveis na página eletrônica do Instituto Brasileiro de Geografia e Estatística (IBGE) ${ }^{7}$, e uma vez que nossa região situa-se fora dos centros econômicos e de poder, pode-se concluir que a agropecuária é fraca e o comércio reduzido aos bens de consumo e a uma pequena indústria de transformação madeireira.

7 Fonte: $<$ https://cidades.ibge.gov.br/brasil/am/humaita/panorama>. Acesso em:10 nov. 2017. 
Em termos de movimentação financeira, o maior fluxo está na folha de pagamento do funcionalismo público, nos três níveis, federal, estadual e municipal e nas forças armadas: exército e marinha.

A oferta de ensino superior público, por meio da Universidade Federal do Amazonas e da Universidade Estadual do Amazonas, como instituiçóes isoladas, terá dificuldade em pôr as bases de uma sólida constituição formativa para a cidadania. Mas, conforme relato de um dos atores entrevistados, emerge a necessidade de parcerias com outros organismos e com a sociedade civil não envolvida diretamente com o ensino superior (Ent. 01) ${ }^{8}$.

Diante do cenário de infraestruturas inadequadas, principalmente para a educação básica, de uma política salarial que não permite maior valorização do profissional em educação em muitos municípios amazônicos, das realidades geográficas que dificultam os deslocamentos, pode se dizer que o acesso de qualidade às novas tecnologias para o aperfeiçoamento e qualificação formativa e a busca por recursos humanos, investimentos e mecanismos de superaçáo dessa realidade são benéficos ao fortalecimento e a um novo rosto na compreensão da relação entre educação e cidadania.

As ações empíricas de cidadania, mencionadas pelos atores entrevistados, organizam-se metodologicamente, em dois níveis: internos e externos. Em algumas situaçóes esses polos intercalam-se, devido à sua natureza no contexto acadêmico e na sociedade, conforme relata o entrevistado: "A formação, por si, já é um processo de cidadania e sua inserção na sociedade. A cidadania não acontece só pelos egressos, mas também pelas pessoas atingidas pelos estudantes" (Ent. 02)

O profissionalismo e a empregabilidade na região não estão ausentes das preocupaçóes dos atores entrevistados, nem poderiam ficar de fora da reflexáo em se tratando de cidadania. "A deficiência de professores, com formação acadêmica superior na região é grande. As pessoas que estão em processo de formação vão atuar e a sociedade vê isto com bons olhos: mais e melhores profissionais" (Ent. 03) ${ }^{10}$.

Outro desafio que se percebe no contexto pesquisado, mas ao mesmo tempo com algum avanço na sociedade local, é a conscientização e formação política. Assim como em muitas sub-regióes brasileiras ainda subsistem práticas abusivas de poder, que mantêm os sujeitos em situaçôes de submissão.

\footnotetext{
8 Ent. 1- Técnica administrativa do campus da Universidade Federal do Amazonas em Humaitá, AM.

9 Ent. 2- Docente do campus da Universidade Federal do Amazonas em Humaitá, AM.

10 Ent. 3- Docente do campus da Universidade Federal do Amazonas em Humaitá, AM.
} 
Chamamos essas situaçóes de contravalores, expressos por um dos atores entrevistados: "Temos um município, infelizmente, administrado pelo coronelismo eleitoral, onde há muitos pactuados aos processos políticos " (Ent. $04)^{11}$. Juntamente com essa prática abusiva do coronelismo, denunciado pela entrevista, emergem outras atitudes consideradas abusivas, como a livre expressão: "O cidadão não expressa o livre direito de exercer a sua vontade, mesmo em passeatas públicas, como tivemos contra a pedofilia, a favor da saúde pública e educaçáo de qualidade, por medo" (Ent. 05) ${ }^{12}$.

Algumas falas que trouxemos para este nosso estudo vêm ilustrar a importância e o quão é significativo o compromisso da educação voltada para a cidadania plena. Isso requer o desenvolvimento de políticas públicas que assumam todo o sistema de ensino multifacetado, composto por instituiçóes públicas e privadas. Conforme alertara Antonio Gramsci (2010, p. 45) nos Cadernos do Cárcere, "[...] se os programas coincidem com a queda geral do nível do corpo de professores, simplesmente não existirá mais nenhuma bagagem a organizar.” Assim, a cidadania casada com a educação é uma conquista composta e derivada da ética, pois o Brasil não é um país pobre, mas um país desigual e injusto e a essência do ensino está diretamente relacionada com os direitos e a dimensão coletiva de consciência a sociedade (PINTO, 2014).

\section{Conclusão}

Cidadania, formação, qualificação não são apenas palavras que continuam presentes no horizonte da educação. Elas refletem a necessidade de implementação de decisões, que passam por políticas públicas relacionadas à educação como um todo. Nesse sentido, resgatamos, mais uma vez, um sentido da Paideia grega embora tenha suas limitaçôes, que supera a visão reduzida ou deformada da educação como um instrumento apenas de instrução. O Estado do Amazonas compreende uma regiáo geográfica de $1.559 .149,074 \mathrm{~km}$ quadrados e apenas 62 municipios (IBGE, 2017). Nesse contexto, o acesso, em sua maioria, se dá por via fluvial. A precaridade dos trasportes também é percebida nas vias terrestres com estradas federais, estaduais e municipais que carecem de boa conservação. $\mathrm{O}$ acesso aéreo, por sua vez, é muito limitado e incompatível com a renda financeira da maioria da população.

11 Ent. 4-Professor do ensino fundamental da Rede Estadual de Humaitá, AM.

12 Ent. 5-Acadêmico do curso de Licenciatura em Pedagogia do campus da Universidade Federal do Amazonas em Humaitá, AM. 
Diante de tal cenário, como poderá a educação contribuir com o resgate social? Acreditamos que não é nem poderá ser a única ferramenta para tal, mas com certeza a educação tem um contributo significativo no sentido de promover ações que poderão colaborar na elaboração de políticas públicas e formação da consciência cidadã. Para isso, além da formação dos educadores, é preciso resgatar o sentido de pertença e autoestima dos próprios amazônidas, no sentido de envolvimento e reivindicação, participação e colaboração. Conforme afirma Gramsci (2010), a sociedade civil é a base de toda formação da sociedade política, e a escola não é apenas um aparelho do Estado, mas uma ferramenta de formação e mudança de paradigmas em vista da cidadania da população.

Para que a sociedade atinja nível satisfatório de desenvolvimento e compromisso social é preciso que a educação abra aos estudantes as possibilidades na multiplicidade das ciências, das letras e das artes no desempenho do binômio ensino-aprendizagem e se transforme em agente gerador de consciência, construtor de cidadania, isso é, a instrução e formação norteadas pelos valores fundamentais da convivência social, como o respeito, a diversidade, a democracia, a justiça e a equidade.

A educação e a ação para a cidadania certamente deverão continuar, por muito tempo, a ser um dos principais elementos da pauta de qualquer sociedade democrática. Os investimentos na educação, quando encarados como tal, também se revertem em economia e desenvolvimento social.

\section{Referências}

BARROS, Ricardo P. de; HENRIQUES, Ricardo; MENDONÇA Rosana. Investimentos em educaçáo e desenvolvimento econômico. Texto para discussão n. 525. Rio de Janeiro: IPEA, nov. de 1997. Disponível em: <http:// www.ipea.gov.br>. Acesso em: 6 jan. 2018.

BAUMAN, Zygmunt. Entrevista sobre educação: os desafios pedagógicos e modernidade líquida. Cad. Pesquisa, Sáo Paulo, v. 39, n. 137, maio/ago. 2009. Disponível em: <http://www.scielo.br/scielo.php?script=sci_arttext\&pid $=$ S0100-15742009000200016>. Acesso em: 6 jan. 2018.

BAUMAN, Zygmunt. Em busca da política. Rio de Janeiro: Jorge Zahar Editor, 2000.

BOBBIO, Norberto. O Futuro da democracia. Tradução de Marco Aurélio Nogueira. Rio de Janeiro: Paz e Terra, 1986. 
BRANDÃO, Carlos Rodrigues. O que é educação? Sáo Paulo: Brasiliense, 1981. BUFFA, Ester. Educação e cidadania: quem educa o cidadão? 14. ed. São Paulo: Cortez, 2010.

CANIVEZ, Patrice. Educar o cidadáo. Campinas: Papirus, 1991.

CLARKE, John et al. Changing Times: perspectives on the Citizen-Consumer. Creating Citizen-Consumers. London: SAGE Publications, 2007.

CORTELLA, Mário Sergio. Algumas concepçóes sobre a relaçáo educação e sociedade. São Paulo: Faculdade de Saúde Pública, USP, 1993. Inédito.

JOSÉ, Emiliano; LEITE, José Corrêa. Entrevista: Carlos Nelson Coutinho. Revista Teoria e Debate, Fundação Perseu Abramo, São Paulo, jun. 2002. Disponível em: <www2.fpa.org.br/entrevista-carlos-nelson-coutinho>. Acesso em: 11 maio 2011.

COSTA, Mário Júlio de Almeida. História do direito português. 3. ed. Coimbra: Almedina, 1999.

CURY, Carlos Roberto Jamil. Educaçáo e contradiçáo. Elementos metodológicos para uma teoria crítica do fenómeno educativo. São Paulo: Cortez e Autores Associados, 1985. (Coleção Educação contemporânea).

DIAS, Edmundo Fernandes. Projetos hegemônicos: a propósito da crise. Universidade e Sociedade, Brasília, DF, Ano XIX, n. 45, p. 8-233, jan. 2010.

FOUCAULT, Michel. Nascimento da biopolítica. Tradução de Pedro Elói Duarte. Lisboa: Edições 70, 2010.

FREITAG, Barbara. Escola, Estado e Sociedade. São Paulo: Edart, 1978.

GINSBORG, Paul. A democracia que não há. Tradução de José Colaço Barreiros. Lisboa: Teorema, 2008.

GRAMSCI, Antonio. Cadernos do Cárcere. O Risorgimento. Notas sobre a história da Itália. v. 5. Tradução de Luiz Sérgio Henrique. 2. ed. Rio de Janeiro: Civilização Brasileira, 2011.

GRAMSCI, Antonio. Cadernos do Cárcere. Os Intelectuais. O princípio educativo. Jornalismo. Tradução de Carlos Nelson Coutinho. 5. ed. Rio de Janeiro: Civilização Brasileira, 2010. v 2. 
GRAMSCI, Antonio. Os intelectuais e a organizaçáo da cultura. 7. ed. Tradução de Carlos Nelson Coutinho. Rio de Janeiro: Civilização Brasileira, 1989.

JAEGER, Werner. Paideia. A formação do homem grego. 6. ed. São Paulo: Saraiva, 2013.

LIMA, Mayumi Souza. A Cidade e a criança. São Paulo: Nobel, 1989.

LIPOVETSKY, Gilles; SERROY, Jean. A Cultura-Mundo. Resposta a uma sociedade desorientada. Tradução de Victor Silva. Lisboa: Ediçóes 70, 2010.

LIPOVETSKY, Gilles. O Crepúsculo do dever. A ética indolor dos novos tempos. Tradução de Fátima Gaspar e Carlos Gaspar. 3. ed. Lisboa: Dom Quixote, 2004.

MARTINS, Sérgio Pinto. Direito do Trabalho. 17. ed. São Paulo: Atlas, 2003.

MARX, Karl; ENGELS, FRIEDRICH. Manifesto do partido comunista. Obras Escolhidas. Tomo I, Lisboa: Ediçôes Avante, 1982.

MARX, Karl; ENGELS, FRIEDRICH. Sulla questione ebraica. Opere complete. v. 3. Roma: Riuniti, 1976.

NASCIMENTO, Amauri Mascaro. Curso de Direito do trabalho. São Paulo: Saraiva, 2003.

PAOLI, Niuvenius Junqueira. Ideologia e hegemonia: as condições de produção da educação. São Paulo: Cortez, 1981.

PINTO, Valmir Flores. Ensino superior como princípio hegemônico de cidadania na sociedade civil - um diálogo com Antonio Gramsci no Sul da Amazônia Brasileira. Tese (Doutorado em Estudos em Ensino Superior)Departamento de Ciências Sociais, Políticas e do Território, Universidade de Aveiro, Aveiro, Portugal, , 2014.

RANCIÈRE, Jacques. O desentendimento - política e filosofia. São Paulo: Ed. 34, 1996.

GIMENO SACRISTÁN, José; PÉREZ GÓMEZ, Ángel I. As funções sociais da escola: da reprodução à reconstrução crítica do conhecimento e da experiência. In: GIMENO SACRISTÁN, José; PÉREZ GÓMEZ, Ángel I. Compreender e transformar o ensino. Porto Alegre: Artmed, 1998. P. 13-25.

SANTARELLI, Enzo. Sobre el fascismo. México: Ediciones Era, 1979. 
SANTOS, Boaventura de Sousa. A Gramática do tempo. Para uma nova cultura política. Porto: Ediçôes Afrontamento, 2006.

TELLES, Vera da Silva. Pobreza e cidadania. São Paulo: Editora 34, 2001.

WOLF, Martin. A reconstruçáo do sistema financeiro global. Lisboa: Dom Quixote, 2009. 